\title{
PEMBELAJARAN BAHASA INDONESIA DI PERGURUAN TINGGI DALAM KONTEKS INTERKULTURAL
}

\author{
Alfiati \\ STAI Madiun \\ alfiati@staimadiun.ac.id
}

\section{Abstract}

Indonesian Language Course is a lesson that develops students' ability to speak Indonesian properly and correctly, because mastery of Indonesian can be used as a measure of one's nationalism as an Indonesian nation. The Indonesian language course also aims to develop students' abilities in organizing ideas or concepts to be communicated to other parties so that there is continuous interaction between ideas and results in an effective knowledge transfer and management process. One of these integration efforts is through intercultural-based learning methods. With an interculturalbased learning process, students are expected to have intercultural competence (interkulturelle competent). Competence is what becomes the provision for adaptation and intercultural communication while maintaining an Indonesian identity and character.

Keywords: Indonesian language, intercultural competence, intercultural communication

\section{Abstrak}

Mata Kuliah Bahasa Indonesia merupakan pelajaran yang mengembangkan kemampuan mahasiswa dalam berbahasa Indonesia dengan baik dan benar, karena penguasaan atas bahasa Indonesia dapat dijadikan ukuran nasionalisme seseorang sebagai bangsa Indonesia. Mata kuliah Bahasa Indonesia juga bertujuan untuk mengembangkan kemampuan mahasiswa dalam mengorganisir ide-ide atau konsep-konsep untuk 
dikomunikasikan kepada pihak lain sehingga terjalin interaksi antar ide yang berkesinambungan dan menghasilkan proses transfer ilmu dan pengelolaan yang berjalan efektif. Upaya pengintegrasian tersebut salah satunya melalui metode pembelajaran berbasis interkultural. Dengan proses pembelajaran berbasis interkultural diharapkan mahasiswa mempunyai kompetensi interkultural (interkulturelle competenzen). Kompetensi itulah yang menjadi bekal untuk melakukan adaptasi dan komunikasi antarbudaya dengan tetap beridentitas dan berkarakter keindonesiaan.

Kata Kunci: Bahasa Indonesia, kompetensi interkultural, komunikasi antar budaya

\section{PENDAHULUAN}

Pada UUD 1945 menerangkan kedudukan bahasa Indonesia sebagai bahasa persatuan sangatlah kuat. Bunyi pasal 36, "Bahasa negara adalah bahasa Indonesia". Pasal ini menjelaskan penggunaan bahasa Indonesia menjadikan kewajiban setiap kepentingan kenegaraan, urusan tata pemerintahan dan dalam perguruan tinggi. Peraturan Pemerintah Republik Indonesia Nomor 19 Tahun 2005 tentang Standar Nasional Pendidikan. Dalam peraturan ini ditetapkan kurikulum tingkat satuan pendidikan tinggi wajib memuat matakuliah Pendidikan Agama, Bahasa Indonesia, Pendidikan Kewarganegaraan, dan Bahasa Inggris. Ketetapan ini menunjukkan bahwa semua perguruan tinggi harus menyelenggarakan mata kuliah tersebut sebagai matakuliah yang wajib ditempuh semua mahasiswa.

Tahun 2013 Kementerian Pendidikan dan Kebudayaan mengubah kurikulum mulai dari pendidikan dasar sampai pendidikan tinggi. Sesuai dengan Undang-Undang No 12 tahun 2012, bahwa perguruan tinggi memiliki otonomi dalam penyusunan kurikulum, namun pada pelaksanaannya diperlukan rambu-rambu yang sama agar dapat mencapai hasil yang optimal. Disamping itu, peserta didik di perguruan tinggi merupakan insan dewasa, sehingga dianggap sudah memiliki kesadaran dalam mengembangkan potensi diri untuk menjadi intelektual, ilmuwan, praktisi, dan atau professional. ${ }^{1}$ Sehubungan dengan itu, maka perubahan pada proses pembelajaran menjadi penting dan akan menciptakan iklim akademik yang akan meningkatkan kompetensi mahasiswa baik hardskills maupun softskills.

\footnotetext{
Alice Edwards and Laura Van Waas, Nationality and Statelessness under International Law, Nationality and Statelessness Under International Law, $2014<$ https://doi. org/10.1017/CBO9781139506007>.
} 
Hal ini sesuai dengan tujuan Pendidikan Tinggi dalam UU No 12 tahun 2012 yaitu menjadi manusia yang beriman dan bertakwa kepada Tuhan Yang Maha Esa dan berakhlak mulia, sehat, berilmu, cakap, kreatif, mandiri, terampil, kompeten, dan berbudaya untuk kepentingan bangsa. Untuk mewujudkan tujuan tersebut, seluruh mahasiswa harus mengikuti pembelajaran mata kuliah dasar umum yang dikenal dengan MKDU (general education). Sebagian dari MKDU telah dinyatakan dalam UU No 12 tahun 2012 sebagai mata kuliah wajib, yaitu Agama, Pancasila, Kewarganegaraan, dan Bahasa Indonesia. Dalam rangka menyempurnakan capaian pembelajaran, maka MKDU ditambah dengan bahasa Inggris, Kewirausahaan, dan mata kuliah yang mendorong pada pengembangan karakter lainnya, baik yang terintegrasi maupun individu. Mata Kuliah Bahasa Indonesia merupakan pelajaran yang mengembangkan kemampuan mahasiswa dalam berbahasa Indonesia dengan baik dan benar, karena penguasaan atas bahasa Indonesia dapat dijadikan ukuran nasionalisme seseorang sebagai bangsa Indonesia. Selain itu, mata kuliah ini juga bertujuan untuk mengembangkan kemampuan mahasiswa dalam mengorganisir ide-ide atau konsep-konsep untuk dikomunikasikan kepada pihak lain sehingga terjalin interaksi antar ide yang berkesinambungan dan menghasilkan proses transfer ilmu dan pengelolaan yang berjalan efektif.

Kompetensi tersebut dapat dicapai mahasiswa dengan optimal jika mahasiswa mendapatkan pengalaman belajar yang bermakna selama proses perkuliahan berlangsung. ${ }^{2}$ Untuk dapat memberikan pengalaman belajar yang bermakna, seorang dosen membutuhkan bahan ajar yang sesuai dengan kebutuhan perkuliahan. Bahan ajar dapat membantu dosen dalam meningkatkan proses pembelajaran menjadi lebih efektif dan efisien. ${ }^{3}$

Dosen memiliki peran yang sangat penting dalam menentukan kuantitas dan kualitas pengajaran yang dilaksanakannya. Oleh sebab itu, dosen harus memikirkan dan membuat perencanaan secara seksama dalam meningkatkan kesempatan belajar bagi mahasiswanya dan memperbaiki kualitas

2 Solehun Solehun, 'Pengembangan Buku Ajar Mata Kuliah Bahasa Indonesia Berorientasi Pendekatan Saintifik Untuk Meningkatkan Kompetensi Mahasiswa S1 Pgsd', Jurnal Review Pendidikan Dasar : Jurnal Kajian Pendidikan Dan Hasil Penelitian, 3.1 (2017), $329<$ https://doi.org/10.26740/jrpd.v3n1.p329-338>.

3 Zuhri, Buku Pegangan Pembelajaran Berorientasi Pada Keterampilan Berpikir Tingkat Tinggi (Jakarta: Dirjen Guru dan Tenaga Kependidikan Kemendikbud, 2018). 
mengajarnya khususnya pembelajaran bahasa Indonesia. ${ }^{4}$ Pembelajaran bahasa Indonesia memegang peranan penting dalam pemahaman pembuatan format yang baik dan benar dalam penelitian yang akan dilakukan mahasiswa kelak, sebagai salah satu syarat lulus dan mendapat gelar sarjana.

Bahan ajar merupakan perangkat pembelajaran yang berisi kompetensi dan materi pembelajaran yang disusun secara sistematis dan runtut untuk mencapai tujuan/kompetensi pembelajaran yang telah direncanakan. ${ }^{5}$ Bahan ajar dapat diartikan sebagai bahan-bahan atau materi pelajaran yang disusun secara lengkap dan sistematis berdasarkan prinsip-prinsip pembelajaran yang digunakan guru dan siswa dalam proses pembelajaran. ${ }^{6}$ Sejalan dengan pernyataan tersebut, bahan ajar yang dikembangkan dalam penelitian ini berbentuk buku ajar mata kuliah umum bahasa Indonesia.

Pendekatan Antarbudaya atau Pendekatan Interkultural adalah sebuah solusi yang tepat dalam memecahkan permasalahan di dalam komunikasi antarbudaya, karena melalui pendekatan tersebut, manusia dapat menghindari penggeneralisasian dan stereotip terhadap orang asing ${ }^{7}$

\section{PENDEKATAN INTERKULTURAL}

Pendekatan Antarbudaya atau Pendekatan Interkultural adalah sebuah solusi yang tepat dalam memecahkan permasalahan di dalam komunikasi antarbudaya, karena melalui pendekatan tersebut, manusia dapat menghindari penggeneralisasian dan stereotip terhadap orang asing. ${ }^{8}$ Penggunaan pendekatan antarbudaya sudah lama dianjurkan oleh Dewan Tinggi Eropa sejak tahun 1970 sebagai prioritas dalam sistem edukasi dan sudah diprak-

${ }^{4}$ Asmara, 'Pengembangan Media Pembelajaran Berbasis Audio Visual Tentang Pembuatan Koloid', Ilmiah Didaktika, 15.2 (2015), 156-78.

5 Labasariyani, 'Penggunaan Video Pembelajaran Sebagai Alat Bantu Dalam Mempersiapkan Bahan Ajar Kalkulus I Untuk Mahasiswa STIMIK STIKOM Indonesia', S@CIES, 5 (2014), 1-3.

6 Riyan Arthur, Yusrina Luthfiana, and Sittati Musalamah, 'Analisa Kebutuhan Pengembangan Media Pembelajaran Pada Mata Kuliah Mekanika Bahan Di Universitas Negeri Jakarta', Jurnal Educational Building, 5.2 (2019), 38-44.

7 N. R. Dewi and others, 'Using Science Digital Storytelling to Increase Students' Cognitive Ability', Journal of Physics: Conference Series, 1006.1 (2018) <https://doi. org/10.1088/1742-6596/1006/1/012020>.

8 Jenna Mittelmeier and others, 'Internationalisation at a Distance and at Home: Academic and Social Adjustment in a South African Distance Learning Context', International Journal of Intercultural Relations, 72.September 2018 (2019), 1-12 <https://doi.org/10.1016/j.ijintrel.2019.06.001>. 
tekkan di sekolah- sekolah Eropa mulai tahun 1990. ${ }^{9}$ Pada awal kemunculannya, pendekatan antarbudaya digunakan untuk memahami antarbudaya kaum imigran.

Budaya adalah salah satu kata yang sulit untuk dedefinisakan. Seorang ahli anthropologi Alfred Kroeber dan Clyde Kluckhohn mencoba mereview definisi budaya yang berbeda pada tahun 1952. Salah satu definisi yang menarik adalah apa yang disampaikan oleh Hall, bahwa "culture is communication and communication is culture. ${ }^{10}$

Oate Franklin memperkuat arti pentingnya komunikasi budaya karena muara dari budaya adalah adanya perbedaan system nilai yang mengacu pada kelompok sosial tertentu. (culture is manifested through different types of regulatiies and that is associated with social groups.). ${ }^{11}$ Bolten mendefinisikan pertemuan dua budaya atau lebih berarti hidup berdampingan (nebeneinander leben), hidup bersama-sama (miteinander leben) adanya interaksi dan inisiatif sosialisasi diri dari kedua pihak bahkan berujung menjadi proses akulturasi. ${ }^{12}$ Tugas interkultural adalah mendorong proses hidup berdampingan menjadi hidup bersama-sama. ${ }^{13}$

Dood mendefinisikan komunikasi antar budaya dilakukan oleh pribadi, antarpribadi, dan kelompok yang mempunyai latara belakang kebudayaan yang berbeda dan perbedaan itu mempengaruhi para pelaku komunikasi. ${ }^{14}$ Sementara Liliweri mendefinisikan komunikasi antarbudaya adalah komunikasi antara dua orang atau lebih yang berbeda latar belakang kebudayaan. ${ }^{15}$

9 Phawani Vijayaratnam, 'Developing Higher Order Thinking Skills and Team Commitment via Group Problem Solving: A Bridge to the Real World', Procedia - Social and Behavioral Sciences, 66 (2012), 53-63 <https://doi.org/10.1016/j. sbspro.2012.11.247>.

${ }^{10}$ Fathur Rokhman and Yuliati, 'The Development of the Indonesian Teaching Material Based on Multicural Context by Using Sociolinguistic Approach at Junior High School', Procedia - Social and Behavioral Sciences, 9 (2010), 1481-88 <https://doi. org/10.1016/j.sbspro.2010.12.353>.

${ }^{11}$ Alessandra Annoni and Serena Forlati, The Changing Role of Nationality in International Law, The Changing Role of Nationality in International Law, $2013<$ https://doi. org/10.4324/9780203436974>.

${ }^{12}$ Edwards and Van Waas.

${ }^{13}$ Desmond Durkin-Meisterernst and others, 'Scientific Methods for Philological Scholarship: Pigment and Paper Analyses in the Field of Manuscriptology', Journal of Cultural Heritage, 17 (2016), 7-13 <https://doi.org/10.1016/j.culher.2015.06.004>.

${ }^{14}$ Edwards and Van Waas.

${ }^{15}$ Mahmut Sami and Hakan Sert, 'P Rimary School 5th Grade Science and 


\section{PEMBELAJARAN BAHASA INDONESIA DI PERGURUAN TINGGI BERBASIS INTERKULTURAL}

Bahan ajar merupakan perangkat pembelajaran yang berisi kompetensi dan materi pembelajaran yang disusun secara sistematis dan runtut untuk mencapai tujuan/kompetensi pembelajaran yang telah direncanakan. ${ }^{16}$ Bahan ajar dapat diartikan sebagai bahan-bahan atau materi pelajaran yang disusun secara lengkap dan sistematis berdasarkan prinsip-prinsip pembelajaran yang digunakan guru dan siswa dalam proses pembelajaran. ${ }^{17}$ Sejalan dengan pernyataan tersebut, bahan ajar yang dikembangkan dalam penelitian ini berbentuk buku ajar mata kuliah umum bahasa Indonesia.

Tujuan akhir atau kompetensi pembelajaran yang direncanakan dalam perkuliahan Bahasa Indonesia dijabarkan dalam CPMK sesuai dengan Surat Keputusan Dirjen Dikti Nomor 43. Kompetensi pembelajaran yang dimaksud tersebut ialah mahasiswa diharapkan mampu menerapkan wawasan kebahasaindonesiaan sebagai perwujudan kecintaan terhadap bahasa Indonesia dan memanfaatkan kemahiran berbahasa Indonesia sebagai media komunikasi ilmiah secara benar, jujur, dan bertanggung jawab. CPMK tersebut kemudian diejawantahkan dalam bentuk RPS untuk memetakan topik-topik pembelajaran sesuai dengan tuntutan yang ada dalam kurikulum. Adapun topik tersebut meliputi (a) kedudukan, fungsi, dan ragam bahasa Indonesia, (b) ejaan bahasa Indonesia, (c) penulisan kalimat dan paragraf, dan (d) penulisan karya ilmiah, yakni penulisan proposal penelitian dan kegiatan, laporan hasil penelitian dan kegiatan, dan artikel ilmiah.

Topik-topik tersebut telah disusun secara runtut untuk dipelajari mahasiswa selama satu semester. Berdasarkan RPS yang telah dipetakan, kemudian dijabarkan menjadi RPP. RPS tersebutlah yang digunakan untuk menyusun materi pembelajaran, strategi pembelajaran, serta evaluasi pembelajaran dalam RPP. Adapun kontrak kuliah merupakan rangkuman tagihan tugas yang harus dipenuhi mahasiswa sebagai pendukung pelaksanaan RPS.

Kultur dalam pembelajaran bahasa dan sastra interkultural membahas

Technology Lesson Book's Investigation of Multiple Intelligence Theory', Procedia - Social and Behavioral Sciences, 174 (2015), 2577-81 <https://doi.org/10.1016/j. sbspro.2015.01.935>.

${ }^{16}$ Syifaul Fuada, 'Pengembangan Buku Ajar Ips-Sejarah Digital Smp', Jurnal Teknik Informatika, 10.1 (2018), 37-48 <https://doi.org/10.15408/jti.v10i1.6969>.

${ }_{17}$ P Wayan Arta Suyasa and others, 'Pengembangan Buku Digital Mata Kuliah Asesmen Dan', 15.2 (2018), 222-33. 
pengkondisian situasi belajar, peran pengajar, peran pebelajar, pengelolaan kelas dan penciptaan kelas yang interkultural, dan penggunaan media.

\section{Pengkondisian Situasi Belajar}

Belajar dapat didefinisikan setiap perubahan tingkah laku yang relatif tetap dan terjadi sebagai hasil latihan atau pengalaman. Menurut pengertian itu, dapat dirumuskan prinsip-prinsip belajar, yaitu

1) belajar adalah perubahan tingkah laku,

2) perubahan tersebut terjadi karena latihan dan pengalaman.

Perubahan yang terjadi pada tingkah laku karena unsur kedewasaan bukan belajar, dan

3) sebelum dikatakan belajar, perubahan tersebut harus relatif permanen dan tetap ada untuk waktu yang cukup lama. Perubahan tingkah laku tersebut disebabkan adanya pengalaman. Apabila kita belajar tentang belajar, sebenarnya kita bicara bagaimana tingkah laku seseorang berubah sebagai akibat dari pengalaman.

Belajar merupakan suatu proses yang dapat menyebabkan terjadinya perubahan tingkah laku karena adanya tanggapan terhadap suatu keadaan tertentu atau adanya proses yang terjadi secara internal di dalam diri seseorang Hal ini menunjukkan bahwa "belajar" atau "mengetahui bahasa" tidak selalu bahkan sering, tidak melibatkan "pengajaran". Yang harus ada dalam keadaan belajar bahasa seperti ini ialah (1) keperluan belajar atau memperoleh suatu sistem komunikasi (bahasa), dan (2) ada tersedia contoh atau "model" komunikasi.

\section{Peran Pengajar}

Pendidikan interkultural bertujuan melatih dan membangun karakter siswa agar mampu bersikap demokratis, humanis, dan pluralis dalam lingkungan mereka. Selain itu, hakikat pembelajaran sastra adalah dapat membantu keterampilan berbahasa pebelajar, meningkatkan pengetahuan budaya, mengembangkan cipta dan rasa, dan menunjang pembentukan watak. Dengan begitu, dapat dikatakan bahwa sastra merupakan sumber berbagai cita rasa di antaranya cita rasa moral dan sosial. Karena itu, sastra sangat layak untuk menjadi sumber pembelajaran bagi para mahasiswa. Pebelajar yang belajar sastra diharapkan memunyai tingkat moral dan sosial yang tinggi. Tugas pengajar atau guru adalah memanusiawikan manusia dengan mengajarkan bahasa dan sastra dalam konteks budaya. Peran 
kebudayaan dalam pembelajaran. dengan adanya pembentukan karakter manusia. Dalam kaitan dengan pembentukan karakter, kebudayaan memiliki nilai-nilai budaya yang berfungsi dan mampu membentuk karakter manusia pendukungnya. Yang diperlukan pendidik atau pengajar adalah harus mampu menggali nilai-nilai kebudayaan yang dibutuhkan untuk membangun karakter bangsa. Selain itu, menemukan sistem pendidikan atau pembelajaran yang tepat diterapkan bagi pebelajar sesuai dengan sifat, kelakuan, dan karakter ke-Indonesiaan.

\section{Peran Pebelajar}

Pebelajar dalam lingkup ruang kelas terdiri atas keberagaman budaya. Hal ini karena pebelajar-pebelajar tersebut sebagai pelaku pembelajaran yang dibesarkan dalam cara, keyakinan, bahkan bisa jadi bahasa yang berbeda pula. Pebelajar apa pun dalam konteks Indonesia pernah mencebur diri dalam bahasa tertentu. Pembelajaran terus dikembangkan agar menunjang terbentuknya pribadi yang imajinatif dan produktif. Semangat pembelajaran tidak pernah lepas dari dua kata kunci, yakni kolaborasi dan kompetisi. Individu secara terus-menerus dikembangkan dalam rangka kerja sama dengan kelompok. Sejalan dengan itu, pembelajaran memerlukan pelbagai pendekatan khusus seperti menerapkan pendekatan intelektual, imajinatif, kreatif, produktif, kolaboratif, kompetitif, dan menggunakan teknologi.

\section{Pengelolaan Kelas dan Penciptaan Kelas yang Interkultural}

Belajar bahasa yang bukan bahasa pertama ini disebut bahasa kedua atau asing. Dari pengalaman diketahui bahwa hal ini sukar; baik bahasa yang digunakan secara umum dalam masyarakat luas (tetapi bukan bahasa rumah tangga), maupun bahasa yang dipakai oleh orang "asing" (yakni di luar lingkungan masyarakat dalam kelompok atau bangsa). Kedua macam bahasa yang bukan bahasa pertama ini disebut secara teknis "bahasa kedua" (yang digunakan masyarakat secara umum) dan "bahasa asing" (yang tidak dipakai masyarakat secara umum). Untuk proses belajar yang sukar seperti inilah perlu dicari dan dikembangkan "tata cara memudahkan" atau disebut "metodelogi". Karena itu, dalam belajar bahasa seperti ini diperlukan guru, artinya ada terlibat kegiatan "mengajar" maka metodologi itu disebut "metodologi pengajaran bahasa", atau lebih jelasnya "metodologi pengajaran bahasa kedua" dan "metodologi pengajaran bahasa asing". Kesadaran multikuluralisme membangunkan parakritikus sastra dari mimpi panjang 
keunggulan satukebudayaan pada masa revolusi yang lalu. Isu lokalitas, antropologi dalam sastra, dan pelbagai bentuk ekspresi local yang terkait sastra lama-kelamaan diangkat. Kebudayaan dalam sastra kemudian mendapatkan tempat dari pelbagai studi kritik sastra pada masa kini.

Pengelolaan Kelas dan Penciptaan Kelas yang Interkultural Belajar bahasa yang bukan bahasa pertama ini disebut bahasa kedua atau asing. Dari pengalaman diketahui bahwa hal ini sukar; baik bahasa yang digunakan secara umum dalam masyarakat luas (tetapi bukan bahasa rumah tangga), maupun bahasa yang dipakai oleh orang "asing" (yakni di luar lingkungan masyarakat dalam kelompok atau bangsa). Kedua macam bahasa yang bukan bahasa pertama ini disebut secara teknis "bahasa kedua" (yang digunakan masyarakat secara umum) dan "bahasa asing" (yang tidak dipakai masyarakat secara umum).

\section{SIMPULAN}

Secara umum tujuan penelitian ini adalah untuk mengembangkan, mengidentifikasi kekurangan, keunggulan, dan kebutuhan buku ajar mata kuliah umum Bahasa Indonesia yang digunakan dalam pembelajaran di Perguruan Tinggi Agama Islam di Kota Madiun. Diharapkan hasil penelitian ini bisa digunakan sebagai buku ajar mata kuliah Bahasa Indonesia yang sesuai di Perguruan Tinggi Agama Islam Se-Karesidenan Madiun. Tujuan lain yaitu mahasiswa diharapkan mampu menerapkan wawasan kebahasaindonesiaan sebagai perwujudan kecintaan terhadap bahasa Indonesia dan memanfaatkan kemahiran berbahasa Indonesia sebagai media komunikasi ilmiah secara benar, jujur, dan bertanggung jawab. 


\section{DAFTAR PUSTAKA}

Annoni, Alessandra, and Serena Forlati, The Changing Role of Nationality in International Law, The Changing Role of Nationality in International Law, 2013 <https://doi.org/10.4324/9780203436974>

Arthur, Riyan, Yusrina Luthfiana, and Sittati Musalamah, 'Analisa Kebutuhan

Pengembangan Media Pembelajaran Pada Mata Kuliah Mekanika Bahan Di Universitas Negeri Jakarta', Jurnal Educational Building, 5.2 (2019), 38-44

Asmara, 'Pengembangan Media Pembelajaran Berbasis Audio Visual Tentang Pembuatan Koloid', Ilmiah Didaktika, 15.2 (2015), 156-78

Dewi, N. R., E. N. Savitri, M. Taufiq, and M. Khusniati, 'Using Science Digital Storytelling to Increase Students' Cognitive Ability', Journal of Physics: Conference Series, 1006.1 (2018) <https://doi. org/10.1088/1742-6596/1006/1/012020>

Durkin-Meisterernst, Desmond, Michael Friedrich, Oliver Hahn, Agnieszka Helman-Wazny, Renate Nöller, and Simone Christiane Raschmann, 'Scientific Methods for Philological Scholarship: Pigment and Paper Analyses in the Field of Manuscriptology', Journal of Cultural Heritage, 17 (2016), 7-13 <https://doi.org/10.1016/j. culher.2015.06.004>

Edwards, Alice, and Laura Van Waas, Nationality and Statelessness under International Law, Nationality and Statelessness Under International Law, 2014 <https://doi.org/10.1017/CBO9781139506007>

Fuada, Syifaul, 'Pengembangan Buku Ajar Ips-Sejarah Digital Smp', Jurnal Teknik Informatika, 10.1 (2018), 37-48 <https://doi.org/10.15408/ jti.v10i1.6969>

Labasariyani, 'Penggunaan Video Pembelajaran Sebagai Alat Bantu Dalam Mempersiapkan Bahan Ajar Kalkulus I Untuk Mahasiswa STIMIK STIKOM Indonesia', S@ CIES, 5 (2014), 1-3

Mittelmeier, Jenna, Bart Rienties, Jekaterina Rogaten, Ashley Gunter, and Parvati Raghuram, 'Internationalisation at a Distance and at Home: Academic and Social Adjustment in a South African Distance Learning Context', International Journal of Intercultural Relations, 72.September 2018 (2019), 1-12 <https://doi.org/10.1016/j. ijintrel.2019.06.001>

Rokhman, Fathur, and Yuliati, 'The Development of the Indonesian Teaching 
Material Based on Multicural Context by Using Sociolinguistic Approach at Junior High School', Procedia - Social and Behavioral Sciences, 9 (2010), 1481-88 <https://doi.org/10.1016/j. sbspro.2010.12.353>

Sami, Mahmut, and Hakan Sert, 'P Rimary School 5th Grade Science and Technology Lesson Book's Investigation of Multiple Intelligence Theory', Procedia - Social and Behavioral Sciences, 174 (2015), 2577-81 <https://doi.org/10.1016/j.sbspro.2015.01.935>

Solehun, Solehun, 'Pengembangan Buku Ajar Mata Kuliah Bahasa Indonesia Berorientasi Pendekatan Saintifik Untuk Meningkatkan Kompetensi Mahasiswa S1 Pgsd', Jurnal Review Pendidikan Dasar: Jurnal Kajian Pendidikan Dan Hasil Penelitian, 3.1 (2017), 329 <https://doi.org/10.26740/jrpd.v3n1.p329-338>

Suyasa, P Wayan Arta, Dewa Gede, Hendra Divayana, Universitas Pendidikan Ganesha, and Universitas Pendidikan Ganesha, 'Pengembangan Buku Digital Mata Kuliah Asesmen Dan', 15.2 (2018), 222-33

Vijayaratnam, Phawani, 'Developing Higher Order Thinking Skills and Team Commitment via Group Problem Solving: A Bridge to the Real World', Procedia - Social and Behavioral Sciences, 66 (2012), 53-63 <https://doi.org/10.1016/j.sbspro.2012.11.247>

Zuhri, Buku Pegangan Pembelajaran Berorientasi Pada Keterampilan Berpikir Tingkat Tinggi (Jakarta: Dirjen Guru dan Tenaga Kependidikan Kemendikbud, 2018) 